\title{
The Sources of Protectionist Drift in Representative Democracies
}

\section{Didier Laussel and Raymond Riezman}

Laussel:

GREQAM, University of Aix-Marseille 2

laussel@univ-aix.fr

Riezman:

University of Iowa

raymond-riezman@uiowa.edu

January, 2000

\begin{abstract}
We analyze a two country-two goods model of international trade in which citizens in each country differ by their specific factor endowments. The trade policy in each country is set by the politician who has been elected by the citizens in a previous stage. Due to a delegation effect citizens generally favor candidates who are more protectionist than they are. The (multiple) one candidate per country-equilibria exhibit a "protectionist drift" owing to this delegation effect and an abstention effect.
\end{abstract}


The Sources of Protectionist Drift in Representative Democracies 1

\section{Introduction}

It is well-known that a one-shot Nash equilibrium between benevolent governments independently setting their trade policies exhibits strictly positive taxes on imports (or exports) in each country ${ }^{1}$. This "tariff war" equilibrium result generalizes the classical "optimum tariff argument" in which governments use tariff policy in order to take advantage of the country's collective market power on international commodities markets and modify the equilibrium terms of trade with the rest of the world.

While this line of research undoubtedly gives insight into the basic incentives existing in actual economies it has been criticized because it relies on the assumption that governments maximize social utility. Trade policy decisions are made by political entities and there has been a vast literature (surveyed suberbly by Rodrik (1997)) examining the link between trade policy and political decision making. Rodrik's survey presents many alternative approaches to this problem but as Rodrik points out, all of them share a single difficulty. Namely, in virtually all of these models trade policy is a second best instrument to implement the implied redistribution of income. Usually, the use of some type of domestic policy would yield a Pareto improvement. Rodrik goes on to point out that based on these models it is not obvious why politically motivated trade policy is anti-trade instead of pro-trade.

What we do is to merge the "tariff war" equilibrium concept with political economy considerations to come up with an explanation for tariffs that is not subject to the Rodrik critique. The political economy approach we follow has its roots in a paper by Wolfgang Mayer(1984). Mayer's paper marked an important step towards a positive approach to trade policy. He showed that if the indirect utility functions of the citizens in each country are single-peaked and the trade policy is determined by direct democracy, then the equilibrium tariff in country $i$ is the tariff preferred by the median voter. The "Mayer equilibrium" is hence equivalent to a two country Nash equilibrium in trade policies where the policies are the ones preferred by the two median voters. In a classical 2 X2X2 framework where the distribution of capital is more skewed than the distribution of labour in the capital rich country then the equilibrium trade policy is more protectionist in the capitalrich country and less protectionist in the capital-poor country. Hence, at a "Mayer equilibrium" there is more protection than at the equilibrium be-

\footnotetext{
${ }^{1}$ see Johnson (1953-4) and Kennan and Riezman (1988)
} 
The Sources of Protectionist Drift in Representative Democracies 2

tween social utiltiy maximizing governments. In this case, considering the influence of political decision making results in a general tendency toward more protectionist equilibria.

We build on Mayer's work by using the majority rule framework but allowing candidates to be chosen endogenously a la Besley and Coate (1997). We find that there is a "protectionist drift" in a representative democracies framework. We borrow from Besley and Coate ((1997), (1998a),(1998b)) and (Osborne and Slivinski (1996)) the idea of "citizen candidates": the future policymaker is chosen in each country among the citizens who are willing to run for election and these citizens are unable to commit to a given policy. Rather, citizens elected implement the policy associated with their given "type" as in Mayer's model. This leads to a "delegation effect". Since the election stage takes place before the trade policy selection and changes in the "type" of the policymaker does have strategic effects on the trade policy equilibrium, voters generally favor the election of somebody whose type differs from their own. We show that there exists a one candidate per countryequilibrium in which the selected policymaker in country $i(i=1,2)$ is the ideal candidate of the median voter and is unabiguously more protectionist than her. Thus, delegation effects produce "protectionist drift". This result is similar to those found by others who have investigated delegation effects in a representative democracy framework for different policy questions (Persson and Tabellini ((1992), (1994), (1996)), Chari, Jones and Marimon (1997), Besley and Coate (1998a)).

We go on to show, however, that besides delegation effects, there is an additionnal source for a protectionist drift in a representative democracy when candidates are purely outcome-motivated. This is what we call the "abstention effect". Not only do candidates wish to delegate to more protectionust colleagues, but these more protectionist colleagues who can win election, prefer still more protetionist candidates than themselves. Therefore, they have an incentive to abstain, that is, not run for election. We show that because of this "abstention effect" there exists a range of electable citizens all of whom are more protectionist than the median voter's most preferred candidate. Thus, candidates who are more protectionist than the ideal candidates of the median voter may run unopposed for election because the only citizens who could defeat them choose not to run. 
The Sources of Protectionist Drift in Representative Democracies 3

\section{The Model}

There are two countries, 1 and 2, producing two goods, A and B, with the help of specific factors. In each sector one unit of specific factor is needed to produce one unit of the good under perfect competition. Hence $y_{i j}$ will denote both the output of good $i$ in country $j$ and the overall stock of the specific factor in sector $i$ of country $j$. There are $N_{j}$ citizens in country $j$. Each citizen $k$ is endowed with $\frac{y_{A j}}{N_{j}}+\theta_{k}$ units of factor $A$ and $\frac{y_{B j}}{N_{j}}$ units of factor $\mathrm{B}$ such that $\sum_{k=1}^{k=N_{j}} \theta_{k}=0$. We suppose for the sake of simplicity that, in each country, the average and median endowments of factor $A$ do coincide. In other words if $m$ is the median voter $\theta_{m}=0$. In the following $\theta_{k}$ will be the citizen $k$ 's "type".

Citizen $k$ has a semi-linear utility function $U\left(c_{A k}, c_{B k}\right)=\alpha c_{A k}-\frac{1}{2} c_{A k}^{2}+c_{B k}$, $\alpha>0$, which is the same in both countries. In equilibrium all consumers in country $j$ will have the same demand for good $A$ which will be denoted $c_{A j}$

Under free trade it is straightforward to show that country $i$ is a net exporter of good A if and only if its output per head in sector $A$ is larger than in country $j$, i.e. $y_{A i} N_{j}-y_{A j} N_{i} \geq 0$. Without any loss of generality we will assume that the output of good $A$ per head is larger in country 1 , hence country 1 exports good $A$.

Assumption 1: $N_{2} y_{A 1}-N_{1} y_{A 2}>0$

Let good B be the numeraire good. The price of the good A in country $j$ is $p_{j}$. Throughout we assume that each country levies import taxes or export taxes on good $A$. The respective specific taxes on exports and imports of good $A$ in countries 1 and 2 are $t_{1}$ and $t_{2}$ and the international price of good $\mathrm{A}$ is defined by $p=p_{1}+t_{1}=p_{2}-t_{2}$. This is the price which one country must pay to the other in order to receive one unit of good $A$ (or the price which it receives when it sells one unit of good $A$ to the other country). In country $j$ citizens receive a uniform lump-sum transfer $f_{j}$ and the government budget constraints in countries 1 and 2 are respectively

$$
\begin{aligned}
t_{1}\left(y_{A 1}-N_{1} c_{A 1}\right) & =N_{1} f_{1} \\
t_{2}\left(N_{2} c_{A 2}-y_{A 2}\right) & =N_{2} f_{2}
\end{aligned}
$$

In country $j$ each citizen $k$ has the same demand $\alpha-p_{j}$ for good $\mathrm{A}$. Hence the market-clearing equilibrium condition for good $\mathrm{A}$ is easily derived 
The Sources of Protectionist Drift in Representative Democracies 4

as

$$
\left(N_{1}+N_{2}\right)(\alpha-p)+N_{1} t_{1}-N_{2} t_{2}=y_{A 1}+y_{A 2}
$$

and then we obtain the equilibrium international price as

$$
p=\alpha+\frac{N_{1} t_{1}-N_{2} t_{2}-y_{A}}{N_{1}+N_{2}}
$$

where $y_{A}=y_{A 1}+y_{A 2}$. It follows that in country 1 we obtain

$$
c_{A 1}=\frac{N_{2}\left(t_{1}+t_{2}\right)+y_{A}}{N_{1}+N_{2}}
$$

for all $k=1,2, . ., N_{1}$, while in country 2 ,

$$
c_{A 2}=\frac{-N_{1}\left(t_{1}+t_{2}\right)+y_{A}}{N_{1}+N_{2}}
$$

for all $k=1,2, . ., N_{2}$.

The budget constraint for individual $\mathrm{k}$ in country $\mathrm{i}$ is given by

$$
p_{i} c_{A i}+c_{B i}=p_{i}\left(\frac{y_{A i}}{N_{i}}+\theta_{k}\right)+\frac{y_{B i}}{N_{i}}+f_{i}
$$

Using (1) and (6) the indirect utility function of a citizen $k$ in country 1 is now obtained as

$$
U_{k}^{1}\left(t_{1}, t_{2}\right)=\alpha c_{A 1}-\frac{1}{2} c_{A 1}^{2}+p\left(\frac{y_{A 1}}{N_{1}}-c_{A 1}\right)+\frac{y_{B 1}}{N_{1}}+\left(p-t_{1}\right) \theta_{k}
$$

with $p$ and $c_{A 1}$ given respectively by equations (3) and (4).

In country 2 the indirect utility function of a citizen $k$ is obtained as

$$
U_{k}^{2}\left(t_{1}, t_{2}\right)=\alpha c_{A 2}-\frac{1}{2} c_{A 2}^{2}+p\left(\frac{y_{A 2}}{N_{2}}-c_{A 2}\right)+\frac{y_{B 2}}{N_{2}}+\left(p+t_{2}\right) \theta_{k}
$$

where $p$ and $c_{A 2}$ given respectively by equations $(3)$ and $(5)$.

Let us now define the game which is played. In the first stage and in each country each citizen decides whether or not she will run for elections in order to represent the community. We assume that a candidate incurs an infinitesimal $\delta>0$ of running for election. The entry decisions are strategic: 
the citizens decide whether to run or not by evaluating the potential benefit from running which, for each of them, depends on the entry decisions of all the other citizens in the same country and in the other country. In the second stage and in each country the polity selects its representative in an election. All citizens have one vote which, if used, must be cast for one of the selfdeclared candidates. The candidate who receives the most votes is elected and, when the candidates tie, all tied candidates win with equal probability. The types of the candidates (i.e. their endowments of the specific factor $\mathrm{A}$ ) are perfectly observable both inside and outside the country. In the third stage the representative selected in the second stage in country $j$ selects the country's trade policy (i.e. the value of $t_{j}$ ). If nobody runs for office the default policy $t_{j}=0$ (laissez-faire) is applied.

Note that we follow Besley and Coate (1997) in supposing that there is no exogenous benefit from holding office ${ }^{2}$ (such as ego rents, resource diversion and the like): candidates are only outcome-motivated. We will indicate below how the removal of this assumption can modify some of our results.

In this paper we will focus on the one-candidate equilibria, i.e. the equilibria where, in each country, one and only one candidate runs unopposed. We will thus avoid altogether the problems associated with multiple voting equilibria when there are more than two candidates who run for election ${ }^{3}$. Besides convenience there are also some good theoretical arguments for giving less attention to multiple-candidate equilibria in one-dimensional models like ours. In the first place, assuming that people vote strategically, contrary to Osborne and Slivinski (1996) who assumed sincere voting, Besley and Coate (1997) have been able to show that, in a one-dimensional model, some very mild assumptions are enough to rule out elections where more than two candidates run. The basic argument is rather intuitive. If three or more candidates tie and if there is a subset of citizens nearly indifferent between two nearby candidates, it is always true (in a large country with continuous variations in endowments) that they will prefer the sure election of one of these two to the lottery between all the candidates. On the other hand, while twocandidate equilibria do exist in our model ${ }^{4}$ and may be characterized they are not robust. In any country where there are two candidates they always

\footnotetext{
${ }^{2}$ For a different assumption see for instance Osborne and Slivinsky (1996).

${ }^{3}$ One encounters these problems as soon as one considers two-candidate equilibria since one has in this case to check that no third candidate is willing to enter.

${ }^{4}$ There can be two candidates in each country or one candidate in one and two candidates in the other.
} 
The Sources of Protectionist Drift in Representative Democracies 6

prefer to withdraw their application in order to let a candidate equidistant from them declare himself and run unopposed. Moreover the latter prefers the equilibrium ${ }^{5}$ in which he is the only candidate to any lottery between two candidates equidistant from him.

\section{Trade Policy Selection}

Let the citizens $r$ and $s$ be the representatives chosen respectively in countries 1 and 2 and $\theta_{r}$ and $\theta_{s}$ their respective "types". The first-order conditions for the trade policy game are derived as

$$
-t_{1} N_{2}+\frac{N_{2} y_{A 1}-N_{1} y_{A 2}-N_{1} N_{2}\left(t_{1}+t_{2}\right)}{N_{1}+N_{2}}-\theta_{r} N_{2}=0
$$

for country 1 and

$$
-t_{2} N_{1}+\frac{N_{2} y_{A 1}-N_{1} y_{A 2}-N_{1} N_{2}\left(t_{1}+t_{2}\right)}{N_{1}+N_{2}}+\theta_{s} N_{1}=0
$$

for country 2 .

It is easy to check that these conditions are both necessary and sufficient (i.e. $U_{r}^{1}$ and $U_{s}^{2}$ are respectively strictly concave with respect to $t_{1}$ and $t_{2}$ ) and that $t_{1}$ and $t_{2}$ are strategic substitutes. A Nash equilibrium of the trade policy game is now any couple $\left(t_{1}\left(\theta_{r}, \theta_{s}\right), t_{2}\left(\theta_{r}, \theta_{s}\right)\right)$ solution of equations $(7)$ and (8). It is straightforward to show that these equations have a unique solution:

$$
\begin{aligned}
& t_{1}\left(\theta_{r}, \theta_{s}\right)=\frac{1}{2} \frac{\left(N_{2} y_{A 1}-N_{1} y_{2 A}\right)-\theta_{s} N_{2} N_{1}-\theta_{r}\left(2 N_{2}+N_{1}\right) N_{2}}{N_{2}\left(N_{1}+N_{2}\right)} \\
& t_{2}\left(\theta_{r}, \theta_{s}\right)=\frac{1}{2} \frac{\left(N_{2} y_{A 1}-N_{1} y_{2 A}\right)+\theta_{r} N_{2} N_{1}+\theta_{s}\left(N_{2}+2 N_{1}\right) N_{1}}{\left(N_{1}+N_{2}\right) N_{1}}
\end{aligned}
$$

As can be seen from equation (9) introducing distributional considerations will tend to reduce the export tax in country 1 since the owners of factor $A$ are hurt by the tax. Hence, the larger is the country 1 policy maker's factor A endowment the lower is the specific tax on country 1 exports of good $A$. The same considerations (see equation (10)) will tend to increase the tariff

\footnotetext{
${ }^{5}$ since it turns out that it is indeed a Nash equilibrium.
} 
in country 2 since the tariff increases incomes of specific factor $\mathrm{A}$ owners in country 2

We next solve for the equilibrium when each country's median voter is elected. One could think of this as a result of Downsian political competition $^{6}$. The equilibrium values of $t_{1}$ and $t_{2}$ can be obtained from (9) and (10) and simply by setting $\theta_{r}=\theta_{s}=0$.

$$
\begin{aligned}
& t_{1}\left(\theta_{r}, \theta_{s}\right)=\frac{1}{2} \frac{\left(N_{2} y_{A 1}-N_{1} y_{2 A}\right)}{N_{2}\left(N_{1}+N_{2}\right)} \\
& t_{2}\left(\theta_{r}, \theta_{s}\right)=\frac{1}{2} \frac{\left(N_{2} y_{A 1}-N_{1} y_{2 A}\right)}{N_{1}\left(N_{1}+N_{2}\right)}
\end{aligned}
$$

In each country the trade policy is the optimal trade policy of the median voter as in Mayer (1984). In this case, country 1 sets a positive export tax and country 2 has a positive tariff. They differ only depending on country size, the larger country setting the larger tax. Thus, the larger the country 2 policy maker's factor A endowment the larger is the specific tax on imports of good $\mathrm{A}$ in country 2. Of course these results are fairly standard. The utility function of any given citizen in either country is indeed strictly concave (and hence single-peaked) and the median voter theorem can be applied. In the next section we determine whether this is an equilibrium in a "citizen candidate" model of political equilibrium.

It is also possible to determine the conditions under which country 1 is a net exporter of good A. Net exports of good A by country 1 are easily obtained as

$$
\frac{1}{2} \frac{\left(\theta_{r}-\theta_{s}\right) N_{2} N_{1}+\left(N_{2} y_{A 1}-N_{1} y_{A 2}\right)}{\left(N_{1}+N_{2}\right)}
$$

It is thus a priori possible than the natural (i.e. free-trade) specialization of countries (determined by the sign of $\left(N_{2} y_{A 1}-N_{1} y_{A 2}\right)$ ) be reversed by a biased choice of policy-makers in one or both countries ${ }^{7}$ : this could occur for instance if the country 2 policy-maker 's endowment in factor $\mathrm{A}$ was much larger than country 1 policy maker's. Of course this can't occur under direct democracy.We will show below that this never occurs in equilibrium under representative democracy.

\footnotetext{
${ }^{6}$ In each country two office-motivated candidates who care only about winning the elections both commit in equilibrium to the policy preferred by the median voter.

7"Natural" specialization occurs not only under free trade but also when the policies are set in each country by the median voters $\left(\theta_{r}=\theta_{s}=0\right)$.
} 
The Sources of Protectionist Drift in Representative Democracies 8

\section{Voting}

In this section we examine a model of "citizen candidates." We assume that, in each country, the citizens can anticipate the utility imputations which arise from the policies selected by each possible couple $\left(\theta_{r}, \theta_{s}\right)$ of policymakers. In country 1 for instance a citizen $k$ will receive an utility level $U_{k}^{1}\left(t_{1}\left(\theta_{r}, \theta_{s}\right), t_{2}\left(\theta_{r}, \theta_{s}\right), \theta_{k}\right)=V^{1}\left(\theta_{r}, \theta_{s}, \theta_{k}\right)$ which depends on its own endowment and on the types of the domestic and the foreign policy- makers. We show in Appendix that $V^{1}$ and $V^{2}$ are strictly concave respectively with respect to $\theta_{r}$ and $\theta_{s}$. We first analyze the delegation effect.

\subsection{The Delegation Effect}

In this section we show that each policy maker wants to delegate the authority to make trade policy to a more protectionist candidate. It is now straightforward to derive explicitly who is the "ideal" policy-maker for a $\theta_{k}$-type citizen of country $j$ given the policy-maker's type in the other country. In country 1

$$
\theta_{r}\left(\theta_{k}, \theta_{s}\right)=\frac{2 N_{1} \theta_{k}\left(N_{1}+N_{2}\right)-\left(N_{2} y_{A 1}-N_{1} y_{A 2}\right)+\theta_{s} N_{2} N_{1}}{\left(3 N_{2}+2 N_{1}\right) N_{1}}
$$

We can now see clearly that the policymaker type which is preferred by a type $\theta_{k}$-citizen generally differs from $\theta_{k}$. This source of this difference lies in the strategic effect of the choice of a policymaker: selecting a candidate with a lower factor $A$ endowment leads to a higher equilibrium value of the export tax $t_{1}$ in country 1 and hence to a larger international price for good A. This is beneficial for all citizens whose types are larger than some critical value; they would like to delegate the trade policy choice to some citizen more protectionist than themselves. $\hat{\theta}_{k}\left(\theta_{s}\right)=\theta_{s}-\left(\frac{y_{A 1}}{N_{1}}-\frac{y_{A 2}}{N_{2}}\right)$ is the critical endowment value in country 1: any citizen with an endowment $\theta_{k}$ larger (resp. lower) than this value favors a candidate with a lower (resp. larger) factor $A$ endowment than her own one (see figure 1 below). The intuition for this result is that a higher export tax results in better terms of trade for owners of factor A, but also lowers the domestic price of good A for any given international price, $p$. This, reduces incomes for voters who own large amounts of factor $A$. So, voters who own less factor $A$ will be more aggressive and charge higher export taxes. In figure 1 all factor owners who own more 
than $\hat{\theta}_{k}$ of factor $\mathrm{A}$ want to delegate the power to make trade policy to a candidate who owns less factor $A$ than they do. These types will clearly be in the majority. $\theta_{r}^{*}$ is the type preferred by the median voter in country 1.

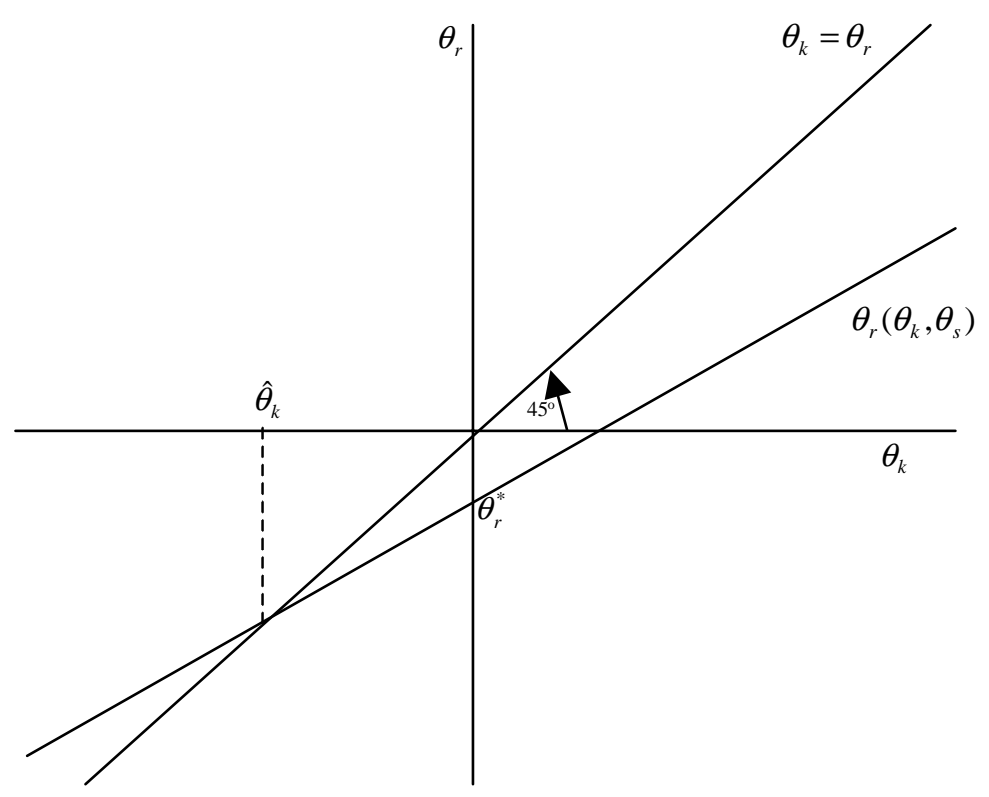

Figure 1

In country 2

$$
\theta_{s}\left(\theta_{k}, \theta_{r}\right)=\frac{2 N_{2} \theta_{k}\left(N_{1}+N_{2}\right)+\left(N_{2} y_{A 1}-N_{1} y_{A 2}\right)+\theta_{r} N_{2} N_{1}}{\left(2 N_{2}+3 N_{1}\right) N_{2}}
$$

and the corresponding critical endowment value $\widehat{\theta}_{k}\left(\theta_{r}\right)=\theta_{r}+\left(\frac{y_{A 1}}{N_{1}}-\frac{y_{A 2}}{N_{2}}\right)$. This case works differently than the export case. In country 2, owners of factor A benefit from higher tariffs in two ways. First, they improve the terms of trade as before, but now increases in the tariff increase the domestic price of good A leading to an increase in income for voters who own large amounts of factor A. So, in the case of the importing country, most factor owners prefer a policymaker who owns more $A$ than they do.Figure 2 illustrates this. Here all factor owners to the left of $\widehat{\theta}_{k}$, clearly a majority, wish to delegate the 
power to make trade policy to someone who owns more factor $A$ than they do. $\theta_{s}^{*}$ is the type preferred by the median voter in country 2 .

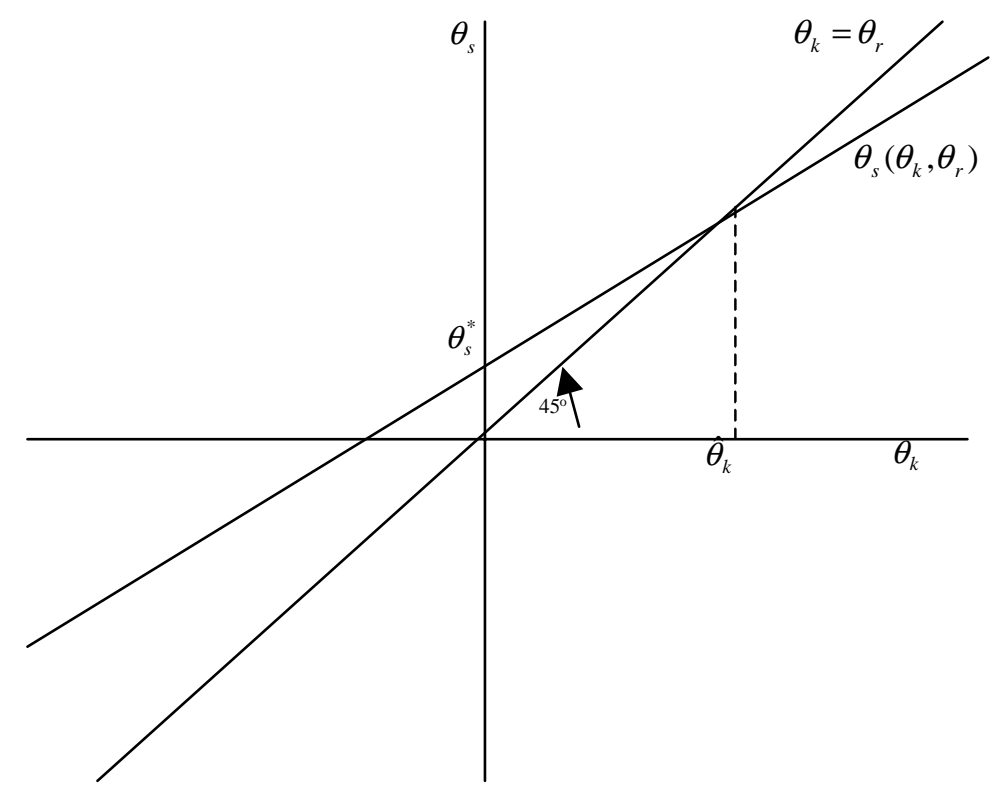

Figure 2

We now define single candidate equilibria.

Definition: $\left(\theta_{r}^{*}, \theta_{s}^{*}\right)$ is a single candidate equilibrium if (i) Given that $\left(\theta_{r}^{*}, \theta_{s}^{*}\right)$ are willing to serve no other candidate who could beat $\left(\theta_{r}^{*}, \theta_{s}^{*}\right)$ in their respctive country wants to serve and (ii) $\left(\theta_{r}^{*}, \theta_{s}^{*}\right)$ prefer serving rather than have nobody serve.

It is now straightforward to see that there exists an equilibrium where, in each country, there is one and only one candidate who is the "ideal policymaker" of the median voter. To solve for this equilibrium set $\theta_{k}=0$ in (13) and (14) and solve the resulting equations to get

$$
\begin{aligned}
\theta_{r}^{*} & =\frac{1}{3} \frac{N_{1} y_{A 2}-N_{2} y_{A 1}}{N_{1}\left(N_{1}+N_{2}\right)} \\
\theta_{s}^{*} & =\frac{1}{3} \frac{N_{2} y_{A 1}-N_{1} y_{A 2}}{N_{2}\left(N_{1}+N_{2}\right)}
\end{aligned}
$$

This equilibrium is illustrated in figure $3 . \theta_{r}\left(\theta_{s}^{*}\right)$ is like a reaction curve that indicates the desired type of the median voter in country 1 given that 
country 2 has selected a type $\theta_{s}^{*}$ as its politcial decision maker. This function is obtained from equation (13) by setting $\theta_{k}=0$ and $\theta_{s}=\theta_{s}^{*}$. $\theta_{s}\left(\theta_{r}^{*}\right)$ is country 2's reaction function obtained by setting $\theta_{k}=0$ and $\theta_{r}=\theta_{r}^{*}$ in equation (14).

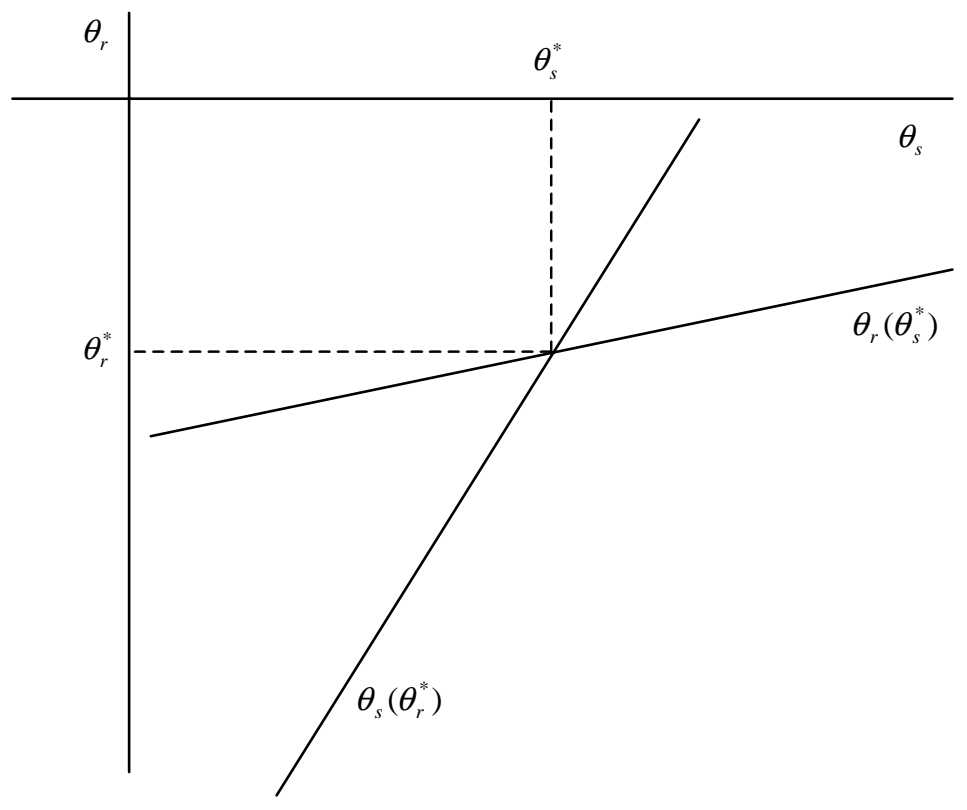

Figure 3

Moreover, these candidates are more protectionist than the respective median voters of their countries: in the exporting country they own less factor A than average and in the importing country they hold a larger than average amount of factor $A$. This follows from a pure delegation effect in each country: delegating the trade policy choice to somebody more protectionist than themselves is a convenient way for the median voters to credibly commit their respective countries to more aggressive trade policies.

Proposition 1 There exists a one candidate per country-equilibrium $\left(\theta_{r}^{*}, \theta_{s}^{*}\right)$ where

$$
\begin{aligned}
& \theta_{r}^{*}=\frac{1}{3} \frac{N_{1} y_{A 2}-N_{2} y_{A 1}}{N_{1}\left(N_{1}+N_{2}\right)} \\
& \theta_{s}^{*}=\frac{1}{3} \frac{N_{2} y_{A 1}-N_{1} y_{A 2}}{N_{2}\left(N_{1}+N_{2}\right)}
\end{aligned}
$$


The Sources of Protectionist Drift in Representative Democracies 12

$$
t_{1}^{*}=t_{2}^{*}=\frac{1}{3}\left(\frac{y_{A 1}}{N_{1}}-\frac{y_{A 2}}{N_{2}}\right)
$$

Proof: (i) clearly $\theta_{r}^{*}=\theta_{r}\left(0, \theta_{s}^{*}\right)$ and $\theta_{s}^{*}=\theta_{s}\left(0, \theta_{r}^{*}\right)$, i.e. $\left(\theta_{r}^{*}, \theta_{s}^{*}\right)$ is a Nash equilibrium where the policymaker selected in each country is the best reply of the median voter of this country to the policymaker chosen in the other country; straightforwardly it is a best reply for the other citizens in both countries to stay outside the electoral competition since they would win with zero probability;

(ii) it remains to show that it is better for the candidates in both countries to run for office rather than to stay outside; remember that we assumed that if there is no candidate the default policy in the country $i$ is laissez faire (i.e. $\left.t_{i}=0\right)$;

Let us consider country 1: laissez faire (and hence not running for office) is formally equivalent to having a policy-maker of type $\widetilde{\theta}_{r}$ who would select $t_{1}\left(\widetilde{\theta}_{r}, \theta_{s}^{*}\right)=0$, ie. such that

$$
\tilde{\theta}_{r}=\frac{1}{3} \frac{\left(N_{2} y_{A 1}-N_{1} y_{A 2}\right)\left(2 N_{1}+3 N_{2}\right)}{\left(N_{1}+N_{2}\right) N_{2}\left(2 N_{2}+N_{1}\right)}>0
$$

It is then straightforward to show that $\widehat{\theta}_{k}\left(\theta_{s}^{*}\right)-\theta_{r}^{*}=\frac{2}{3} \frac{-N_{2} y_{A 1}+N_{1} y_{A 2}}{N_{1} N_{2}}<0$ and hence $\theta_{r}\left(\theta_{r}^{*}, \theta_{s}^{*}\right)<\theta_{r}^{*}<0<\widetilde{\theta}_{r}$ : the strict concavity of $V^{1}\left(\theta_{r}, \theta_{s}, \theta_{k}\right)$ with respect to $\theta_{r}$ now implies that $V^{1}\left(\theta_{r}^{*}, \theta_{s}^{*}, \theta_{r}^{*}\right)>V^{1}\left(\widetilde{\theta}_{r}, \theta_{s}^{*}, \theta_{r}^{*}\right)$;

in country 2 now laissez faire is equivalent to having a default policymaker of type

$$
\widetilde{\theta}_{s}=\frac{1}{3} \frac{-\left(3 N_{1}+2 N_{2}\right)\left(N_{2} y_{A 1}-N_{1} y_{A 2}\right)}{\left(N_{1}+N_{2}\right) N_{1}\left(N_{2}+2 N_{1}\right)}<0
$$

whereas $\hat{\theta}_{k}\left(\theta_{r}^{*}\right)-\theta_{s}^{*}=\frac{2}{3} \frac{N_{2} y_{A 1}-N_{1} y_{A 2}}{N_{1} N_{2}}>0$ and hence $\theta_{s}\left(\theta_{r}^{*}, \theta_{s}^{*}\right)>\theta_{s}^{*}>0>$ $\widetilde{\theta}_{s}$ : one again the strict concavity of $V^{2}\left(\theta_{s}, \theta_{r}, \theta_{k}\right)$ with respect to $\theta_{s}$ implies that $V^{2}\left(\theta_{s}^{*}, \theta_{r}^{*}, \theta_{s}^{*}\right)>V^{2}\left(\widetilde{\theta}_{s}, \theta_{r}^{*}, \theta_{s}^{*}\right)$.

It is interesting to compare the values of $t_{1}$ and $t_{2}$ at the above equilibrium with their equilibrium values under direct democracy. This can be thought of as measuring the delegation effect.It is straightforward to show that the import and export taxes are both larger under representative democracy if and only if $\frac{N_{i}}{N_{1}+N_{2}}<\frac{2}{3}, i=1,2$. That is, if countries are roughly the same size the delegation effect results in a higher exoport tax and a higher tariff. However 
if, for instance, $\frac{N_{1}}{N_{1}+N_{2}}>\frac{2}{3}$ the equilibrium value of $t_{1}$ is still larger than $t_{1}(0,0)$ but the equilibrium value of $t_{2}$ is now lower than $t_{2}(0,0)$ : strategic commitment through the election of a policymaker more protectionist than the median voter allows a "big" country to obtain a less protectionist trade policy from the smaller country.

\subsection{The Abstention Effect}

In contrast with the model of representative democracy developped by Besley and Coate (1997), (1998) (see also Osborne and Slivinski (1996)) in which the preferred candidate of any given citizen is a citizen of the same type, there exist here other one-candidate equilibria than the equilibrium where the policymakers who are chosen are the preferred candidates of the median voters. Implicit in Proposition 1 is the notion that voters $\theta_{r}^{*}$ and $\theta_{s}^{*}$ are willing to run for office and serve if elected. There is one difficulty with this assumption. Both type $\theta_{r}^{*}$ and $\theta_{s}^{*}$ voters prefer a citizen of different type than themselves to run (see figure 1). Let us consider for instance the electoral competition process in country 2 (the same analysis can be applied to the electoral competition in country 1). Let us show that there can be in country 2 , for a given type $\theta_{r}$-policymaker selected in country 1 , a type $\theta_{s}$ candidate such that $\theta_{s} \neq \theta_{s}\left(0, \theta_{r}\right)$ running unopposed. For this to happen it is necessary and sufficient that (a) this candidate prefers the political outcome following her election to the default (laissez-faire) outcome, (b) there exists no citizen who would prefer her own election to the election of the single candidate and who would be preferred to her opponent by a majority of citizens.

Note that the first condition is satisfied if and only if the single candidate strictly prefers her own election to the election of some other citizen who would favor laissez-faire (i.e. $t_{2}=0$ ). It is straightforward from (10) to derive the type $\widetilde{\theta}_{s}\left(\theta_{r}\right)$ of such a citizen:

$$
\tilde{\theta}_{s}\left(\theta_{r}\right)=\frac{-N_{2} y_{A 1}+N_{1} y_{A 2}-\theta_{r} N_{2} N_{1}}{N_{1}\left(N_{2}+2 N_{1}\right)}=-\frac{N_{2}}{N_{2}+2 N_{1}} \hat{\theta}_{k}\left(\theta_{r}\right)
$$

We will come back to this condition below. Let us now determine exactly who are the citizens who would prefer their own election to the election of a $\theta_{s}$-type citizen. First one has to determine the type $\theta_{k}^{*}$ of citizen who is indifferent between herself and the type $\theta_{s}$. Given the linear-quadratic nature 
of the indirect utility functions $V$, the value of $\theta_{k}^{*}$ is determined by solving the equation $\theta_{s}-\theta_{s}\left(\theta_{k}^{*}, \theta_{r}\right)=\theta_{s}\left(\theta_{k}^{*}, \theta_{r}\right)-\theta_{k}^{*}$. Using equation (14) we obtain

$$
\theta_{k}^{*}=\frac{\theta_{s} N_{2}\left(2 N_{2}+3 N_{1}\right)-2\left(y_{A 1} N_{2}-N_{1} y_{A 2}\right)-2 \theta_{r} N_{2} N_{1}}{\left(2 N_{2}+N_{1}\right) N_{2}}
$$

There are now only two cases to be considered:

(i) $0<\theta_{s}\left(0, \theta_{r}\right)<\widehat{\theta}_{k}\left(\theta_{r}\right)^{8}$

A sufficient condition for a $\theta_{s}$-type candidate to run unopposed is simply that $\theta_{s} \geq \theta_{s}\left(0, \theta_{r}\right)$ and $\theta_{k}^{*} \leq 0^{9}$, i.e. $\theta_{s}\left(0, \theta_{r}\right) \leq \theta_{s} \leq 2 \theta_{s}\left(0, \theta_{r}\right)\left(<\hat{\theta}_{k}\left(\theta_{r}\right)\right)$. In figure 4 let $A=\theta_{s}\left(0, \theta_{r}\right)$ and $B=2 \theta_{s}\left(0, \theta_{r}\right)$ and for simplicity call a candidate with an endowment of $\theta_{s}\left(0, \theta_{r}\right)\left(2 \theta_{s}\left(0, \theta_{r}\right)\right)$ candidate $A(B)$.

Any candidate to the left of $A\left(\theta_{s}<\theta_{s}\left(0, \theta_{r}\right)\right)$ would be defeated by candidate $A$ since the median voter (type $\theta_{s}\left(0, \theta_{r}\right)$ ) and all voters to the right of the median voter would prefer $A$. In addition, $A$ would serve himself rather than have someone to his left be elected. For a candidate to the right of $B\left(\theta_{s}>2 \theta_{s}\left(0, \theta_{r}\right)\right)$, one can show using equation $(20)$ that the median voter would prefer to run himself (and would clearly win) rather than have a candidate to the right of $B$ in office. That leaves candidates between $A$ and $B$ as possible winners of single candidate elections. If any candidate between $A$ and $B$ chooses to run they will win.

Even the extreme candidate $B$ gets all votes to the right of the median voter and candidates to the left of $B$ do even better. Using equation (20) one can easily show that $A$ prefers any candidate in the $A B$ range to running himself. In addition, all voters in the $A B$ range want a candidate to their right to run and would prefer to run themselves rather than have someone to their left win. Therefore, any candidate between $A$ and $B$ is a one candidate equilibrium. Candidates closer to $A$ get larger winning vote shares but would always prefer that someone to their right actually run.

The distance $O A$ in figure 4 measures the delegation effect. The median voter wants to delegate authority to a voter with $O A$ more of the specific factor than he has. The distance from $A$ to $B$ measures the abstention effect. The voter at $A$ although in some sense the most "popular" candidate

${ }^{8}$ Note that a sufficient condition for this set of inequalities is $\widehat{\theta}_{k}\left(\theta_{r}\right)>0$ since $\left.\theta_{s}\left(0, \theta_{r}\right)\right)=\widehat{\theta}_{k}\left(\theta_{r}\right) \frac{N_{1}}{2 N_{2}+3 N_{1}}$.

${ }^{9}$ Note that all the citizens located at the right of $\theta_{k}^{*}$ strictly prefer a type $\theta_{s}$-candidate to a candidate located at $\theta_{k}^{*}$ or at her left. Hence if $\theta_{k}^{*}<0$ the type $\theta_{s}$-candidate is chosen by a majority of voters. 


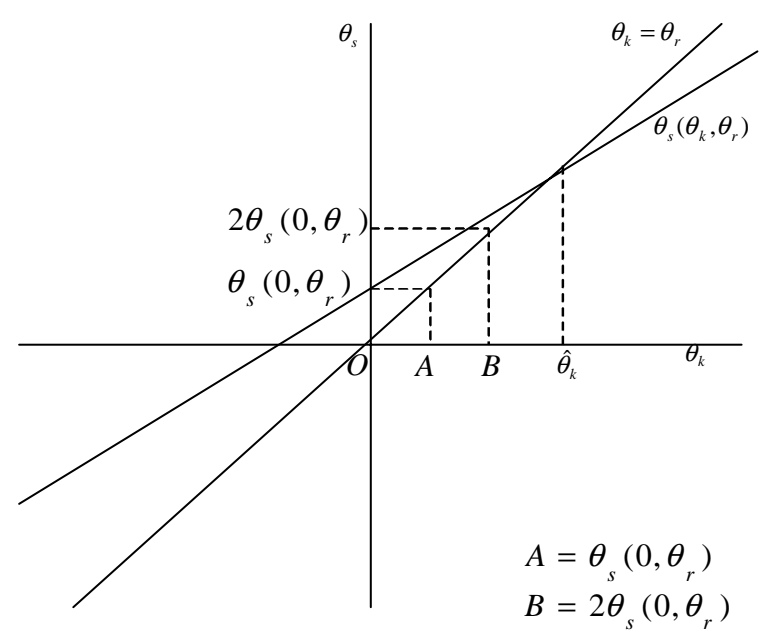

Figure 1: Figure 4

actually prefers someone to his right to run. In fact, he prefers any voter between $A$ and $B$ to himself. So, any of those voters represent potential one candidate equilibria. As you move from $A$ to $B$ the candidates are decreasing in "popularity" and increasing in their "eagerness" to run for election.

(ii) When $\hat{\theta}_{k}\left(\theta_{r}\right)<\theta_{s}\left(0, \theta_{r}\right)<0$ a sufficient condition for a $\theta_{s}$-type candidate to run unopposed is simply that $\theta_{s} \leq \theta_{s}\left(0, \theta_{r}\right)$ and $\theta_{k}^{*} \leq 0$, i.e. $2 \theta_{s}\left(0, \theta_{r}\right) \leq \theta_{s} \leq \theta_{s}\left(0, \theta_{r}\right)$. The logic is the same as case (i) above so we will not repeat the argument.

The same analysis can be applied to the electoral competition in country 1. Using equations (13), (14), and (20) we can obtain a complete characterization of the set of one-candidate equilibria.

Proposition 2 Given Assumption 1 any pair $\left(\theta_{r}, \theta_{s}\right)$ such that

$$
\begin{gathered}
\frac{-2\left(N_{2} y_{A 1}-N_{1} y_{A 2}\right)+2 \theta_{s} N_{2} N_{1}}{\left(3 N_{2}+2 N_{1}\right) N_{1}} \leq \theta_{r} \leq \frac{-\left(N_{2} y_{A 1}-N_{1} y_{A 2}\right)+\theta_{s} N_{2} N_{1}}{\left(3 N_{2}+2 N_{1}\right) N_{1}} \\
\frac{\left(N_{2} y_{A 1}-N_{1} y_{A 2}\right)+\theta_{r} N_{2} N_{1}}{\left(2 N_{2}+3 N_{1}\right) N_{2}} \leq \theta_{s} \leq \frac{2\left(N_{2} y_{1}-N_{1} y_{2}\right)+2 \theta_{r} N_{2} N_{1}}{\left(2 N_{2}+3 N_{1}\right) N_{2}}
\end{gathered}
$$

is a one candidate per country-equilibrium. 
The Sources of Protectionist Drift in Representative Democracies 16

Obviously the equilibrium of Proposition 1 (where the single candidate in each country is the preferred candidate of the median voter) is one of these equilibria. There are in addition infinitely many other equilibria as shown in Figure 5 below. At the more "extremist" of the symmetric equilibria (point $\mathrm{B}$ in Figure 5) one obtains

$$
\begin{aligned}
& \theta_{r}^{* *}=-\frac{2}{3} \frac{\left(N_{2} y_{A 1}-N_{1} y_{A 2}\right)\left(N_{1}+2 N_{2}\right)}{\left(3 N_{1} N_{2}+2 N_{2}^{2}+2 N_{1}^{2}\right) N_{1}} \\
& \theta_{s}^{* *}=\frac{2}{3} \frac{\left(N_{2} y_{A 1}-N_{1} y_{A 2}\right)\left(N_{2}+2 N_{1}\right)}{N_{2}\left(3 N_{1} N_{2}+2 N_{2}^{2}+2 N_{1}^{2}\right)}
\end{aligned}
$$

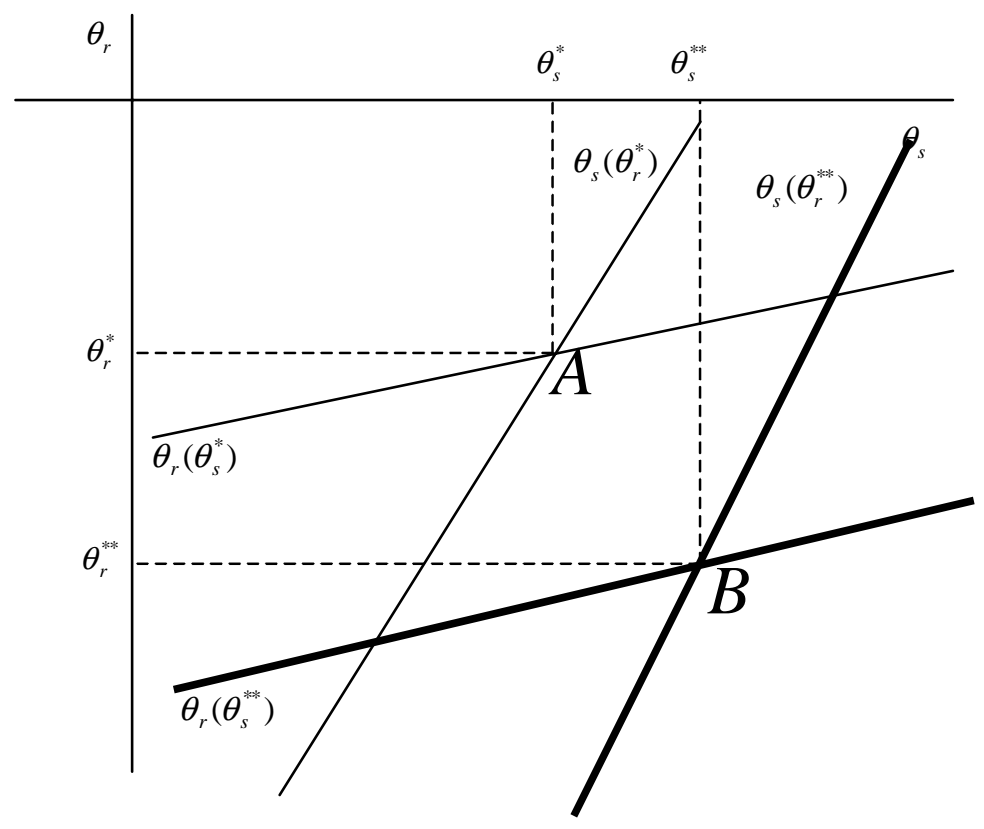

Figure 5

If these most "extremist" candidates are chosen the resulting tariff and export tax is (substituting equations (21) and (22) into equations (9) and (10))

$$
t_{1}=\frac{\left(2 N_{2}+N_{1}\right)\left(2 N_{1}^{2}+5 N_{1} N_{2}+4 N_{2}^{2}\right)\left(N_{2} y_{A 1}-N_{1} y_{A 2}\right)}{6 N_{1}\left(2 N_{2}^{2}+3 N_{1} N_{2}+2 N_{1}^{2}\right) N_{2}\left(N_{1}+N_{2}\right)}
$$


The Sources of Protectionist Drift in Representative Democracies 17

$$
t_{2}=\frac{\left(N_{2}+2 N_{1}\right)\left(4 N_{1}^{2}+5 N_{1} N_{2}+2 N_{2}^{2}\right)\left(N_{2} y_{A 1}-N_{1} y_{A 2}\right)}{6 N_{1}\left(2 N_{2}^{2}+3 N_{1} N_{2}+2 N_{1}^{2}\right) N_{2}\left(N_{1}+N_{2}\right)}
$$

Note that the extent of the "protectionist drift" depends not only on the extent of the delegation and absention effects in both countries but also on the strategic interation between the two countries. In fact, the strategic complementarity between the policymakers limits the impact of the delegation and abstention effects.as can be seen by noting that the value of $\theta_{s}^{*}$ above is less than twice the value of $\theta_{s}^{* *}$. However, it is still the case that if the country sizes are not too dissimilar then both the export tax and the tariff are higher than when only the delegation effect is considered (Proposition 1.) Thus, both the delegation and abstention effects tend to result in higher protection levels.

\section{Concluding remarks}

In this paper we used a two-country framework to show that a majority of citizens in both countries favor the election of representatives who are more protectionist than themselves. The key for this result is that the election of a representative is a way for the citizens to commit their country to a more aggressive trade policy. We demonstrated the existence of an infinite number of one candidate per country equilibria. Provided that the countries sizes are not too dissimilar, are all unambiguously more protectionist than the "Mayer equilibrium", i.e. the median voter in each country selects trade policy. This "protectionist drift" may be ascribed first to a delegation effect and an abstention effect. The delegation effect occurs because all citizens want to choose a policy maker who is more aggresive than they are. The abstention effect is more subtle. This more protectionist citizen who is chosen policy maker himself wishes to delegate to one more protectionist still. What we show is that since there are other viable candidates the candidate most preferred by the median voter may choose to "abstain" from running for office in order to allow someone more protectionist than himself to run. This results in even greater protectionist drift than would be present with only the delegation effect.

Future research will consider how these conclusions might change if there are costs or benefits from holding office. Thus, policymakers could be "officemotivated", i.e. they derive utility from being in office (salaries, ego-rents 
The Sources of Protectionist Drift in Representative Democracies 18

and the like) or holding office could involve costs (loss of income, privacy, etc.).

\section{References}

Besley, T. and S.Coate (1997). An Economic Model of Representative Democracy, Quarterly Journal of economics 112: 85-114.

Besley, T. and S.Coate (1998a). Centralized vs Decentralized Position of Local Public Goods: A Political Economy Analysis, mimeo, London School of Economics.

Besley, T. and S.Coate (1998b). Sources of Inefficiency in a Representative Democracy: A Dynamic Analysis, American Economic Review 88: $139-156$.

Chari, V.V., L.E. Jones and R. Marimon (1997). The Economics of Split-ticket voting in Representative Democracies, American Economic Review 87: 957-976.

Mayer, W. (1984). Endogenous Tariff Formation, American Economic Review 74: 970-985.

Persson, T. and G. Tabellini (1992). The Politics of 1992: Fiscal Policy and European Integration, Review of Economic Studies 59: 689-701.

Persson, T. and G. Tabellini (1994). Representative Democracy and Capital Taxation, Journal of Public Economics 85: 53-70.

Persson, T. and G. Tabellini (1996). Federal Fiscal Constitutions: RiskSharing and Moral Hazard, Econometrica 64: 623-646.

\section{APPENDIX}

Lemma $3 V^{1}$ (resp. $\left.V^{2}\right)$ is strictly concave with respect to $\theta_{r}\left(\right.$ resp. $\left.\theta_{s}\right)$. 
The Sources of Protectionist Drift in Representative Democracies 19

Proof: It will be enough to prove the strict concavity of $V^{1}$ (the concavity of $V^{2}$ is proved using a similar argument). From the definition of $V^{1}($ $\left.\theta_{r}, \theta_{s}, \theta_{k}\right)$ and equations $(3),(4),(7)$ and $(8)$ we obtain

$$
\frac{\partial V^{1}}{\partial \theta_{r}}=\frac{N_{1} N_{2}\left(\theta_{k}+2 t_{1}\left(\theta_{r}, \theta_{s}\right)+t_{2}\left(\theta_{r}, \theta_{s}\right)\right)-\left(y_{A 1} N_{2}-N_{1} y_{A 2}\right)}{N_{1}\left(N_{1}+N_{2}\right)}
$$

and then, using again equations (7) and (8),

$$
\frac{\partial^{2} V^{1}}{\partial \theta_{r}^{2}}=\frac{-N_{2}\left(3 N_{2}+2 N_{1}\right)}{\left(N_{1}+N_{2}\right)^{2}}<0
$$

$\square$

$$
\frac{N_{1} N_{2}\left(\theta_{k}+2 \frac{1}{2} \frac{\left(N_{2} y_{A 1}-N_{1} y_{2 A}\right)-\theta_{s} N_{2} N_{1}-\theta_{r}\left(2 N_{2}+N_{1}\right) N_{2}}{N_{2}\left(N_{1}+N_{2}\right)}+\frac{1}{2} \frac{\left(N_{2} y_{A 1}-N_{1} y_{2 A}\right)+\theta_{r} N_{2} N_{1}+\theta_{s}\left(N_{2}+2 N_{1}\right) N_{1}}{\left(N_{1}+N_{2}\right) N_{1}}\right)-(y}{N_{1}\left(N_{1}+N_{2}\right)}
$$
$-\frac{1}{2 N_{1}} \frac{-2 \theta_{k} N_{2} N_{1}^{2}-2 \theta_{k} N_{2}^{2} N_{1}-3 N_{1} N_{2} y_{A}+3 N_{1}^{2} y_{2 A}+3 \theta_{s} N_{2} N_{1}^{2}+9 N_{1} \theta_{r} N_{2}^{2}+5 \theta_{r} N_{2} N_{1}^{2}+N_{2}^{2} y_{A}-N_{2} N_{1} y_{2 A}-\theta_{s} N_{2}^{2} N_{1}}{\left(N_{1}+N_{2}\right)^{2}}=$ 0 